\title{
El derecho a la propiedad como dimensión del derecho a la identidad
}

\author{
MARÍA DEL CARMEN DELGADO MENÉNDEZ*
}

\begin{abstract}
SUMARIO: I. INTRODUCCIÓN.- II. LAS DOS ESFERAS DEL DERECHO A LA IDENTIDAD.- III. EL DERECHO A LA PROPIEDAD COMO DERECHO FUNDAMENTAL.- IV. LAS REFORMAS HACIA LA INCLUSIÓN.- V. RESULTADOS DE LOS PROGRAMAS DE FORMALIZACIÓN DE LA PROPIEDAD EN EL PERÚ.VI. PRINCIPALES RETOS Y LECCIONES APRENDIDAS.
\end{abstract}

\section{INTRODUCCIÓN}

El presente artículo busca introducir a los lectores en el tema del derecho a la identidad bajo una aproximación distinta, esto es, desde una óptica más comprensiva que lo extiende al ámbito de los derechos de propiedad. Se pretende demostrar cómo el acceso a la propiedad por parte de las mayorías pobres, hoy excluidas del amparo de la ley y de los beneficios que esta brinda, constituye un presupuesto indispensable para garantizar el derecho a la identidad en su dimensión más amplia.

De acuerdo con el Informe Final de la Comisión para el Empoderamiento Legal de los Pobres (CLEP) ${ }^{1}$ de 2008:

[...] la mayoría de las personas pobres no viven bajo el amparo del derecho, sino alejados de la protección de la ley y de las oportunidades que ésta ofrece. Sus actividades se rigen según normas e instituciones locales informales, y ahí donde no se encuentran excluidos del sistema legal, con frecuencia se hallan oprimidos por el mismo. Debido a que los pobres carecen de derechos reconocidos son vulnerables al abuso por parte de las autoridades que discriminan, buscan sobornos o favorecen los intereses de gente influyente que podría desear que los pobres no compitan económicamente o que busca expulsarlos de sus tierras. Semejante discriminación trae enormes consecuencias [...].

Al referirse a la magnitud de la exclusión, la CLEP manifiesta que:

[...] al menos cuatro mil millones de personas (70\% de la población mundial) están excluidas del Estado de derecho [...] es una minoría de

* Profesora asociada de la Facultad de Derecho de la Pontificia Universidad Católica del Perú, a cargo del cursodeDerechoCivil1 desde1990,y gerentelegaldel InstitutoLibertady Democracia(ILD). Esespecialista enderechos depropiedad; hadiseñadoreformasinstitucionalesparalacapitalizacióndeactivosprediales yempresarialesyhadirigidoprogramasnacionaleseinternacionalesparasuimplementación. Esteartículo contiene algunos de los principales hallazgos de las investigaciones y programas en los que la autora ha participado en calidad de investigadora principal y gerente legal del ILD.

1 El reporte, presentado en Nueva York el 13 de junio de 2008, fue producto de investigaciones, análisis y consultasenmás deveintepaísesen vías dedesarrollo.CLEPfuecreadaporungrupodepaísesendesarrollo e industrializados, entreellos, Canadá, Dinamarca, Egipto, Finlandia, Guatemala, India, Islandia, Noruega, ReinoUnido,Sudáfrica, Sueciay Tanzania. Haestado integradapor Madeleine Albrighty HernandodeSoto (copresidentes) y por eminentes políticos y especialistas de todo el mundo, con experiencia reconocida en la planificación e implementación de procesos complejos de reforma en pro del bien público. CLEP fue patrocinada por el Programa de las Naciones Unidas para el Desarrollo. 
la población mundial la que puede aprovechar las normas y reglamentaciones jurídicas. La mayoría de la humanidad se halla del otro lado de la ventana, mirando hacia adentro, incapaz de contar con la protección de la ley y sin posibilidades de ingresar al mercado nacional, y mucho menos al mercado mundial $[\ldots]^{2}$.

Por otro lado, «[...] resulta evidente que a pesar de las iniciativas, programas y reformas diseñados e implementados durante las últimas dos décadas, en la mayoría de países en vías de desarrollo, el ordenamiento jurídico no ha sido capaz de proveer a los titulares de derechos prediales los mecanismos legales necesarios que les permitan beneficiarse de los principales efectos que un sistema legal moderno e inclusivo brinda $\left[\ldots . »^{3}\right.$. Como resultado, «[...] la mayoría de las personas pobres del mundo carecen de derechos de propiedad efectivos; no poseen seguridad de la tenencia y no son conscientes de sus derechos legales o bien no pueden ejercerlos» ${ }^{4}$. De acuerdo con una investigación realizada por el Instituto Libertad y Democracia (ILD) a principios de 2006, a pedido del Banco Interamericano de Desarrollo (BID) ${ }^{5}$, «[...] la situación de extralegalidad estaría afectando al 44\% de los predios urbanos y al $88 \%$ de los predios rurales en el Perú. Esta situación es similar a la del resto de países de Latinoamérica, en los que la extralegalidad se extiende al $65 \%$ de predios urbanos y al $76 \%$ de predios rurales ${ }^{6}$.

\section{LAS DOS ESFERAS DEL DERECHO A LA IDENTIDAD}

La concepción moderna del derecho a la identidad, tal y como está consagrada en diversas constituciones, legislaciones y jurisprudencias, nos permite apreciar este derecho en su doble dimensión. La primera está constituida por la identidad estática o primaria - comúnmente conocida como «identificación»—, que se refiere básicamente a la identificación física, biológica o registral de un sujeto - mediante señas tales como el nombre, el seudónimo, la imagen, el sexo, el lugar y fecha de nacimiento, las huellas digitales, la filiación, la nacionalidad, etcétera-? La segunda atañe a la llamada identidad dinámica, que va más allá de la identidad estática, y comprende al conjunto de atributos y calificaciones de la persona, una identidad que se proyecta socialmente, que se enriquece constantemente, que evoluciona y cambia. Se trata de la «verdad personal» de cada sujeto, que se pone de manifiesto a través de la «proyección social» de la persona y que implica el «derecho de cada uno a que no se le desconozcan sus propias acciones», a que «no se le atribuya

2 CLEP.InformeFinal. «Laley: laclaveparaeldesarrollosinexclusiones».Volumen 1.Nueva York: Programa de las Naciones Unidas para el Desarrollo, 2008, p. 3.

3 Delgado, Maríadel Carmen. «Laformalización de la propiedadenel Perú: principales reformas para facilitar el saneamiento, registro y uso económico de predios en áreas urbanas". Actualidad Jurídica, diciembre de 2008, p.61, Lima.

4 CLEP. Op. cit., p. 41. En Delgado. Op. cit., p. 61.

5 Los países objeto del estudio fueron Argentina, Bolivia, Colombia, República Dominicana, Ecuador, El Salvador, Guatemala, Haití, Honduras, México, Panamá y Perú.

6 Delgado. Op. cit., p. 69.

7 Fernández Sessarego, Carlos. El derecho a la identidad personal. Buenos Aires: Astrea, 1992, pp. 87 y 108. 
la paternidad de acciones que no le son propias» ${ }^{8}$ y también a que se le reconozca como titular de sus actividades reales y potenciales, así como de sus principales activos, constituidos en la gran mayoría de casos por terrenos, viviendas y pequeños negocios ${ }^{9}$.

$\mathrm{Al}$ referirse a las dos esferas del derecho a la identidad antes señaladas, Carlos Fernández Sessarego nos dice que se trata de:

[...] un nuevo derecho destinado a tutelar la «verdad personal», lo que uno realmente es $[\ldots]$. Cuando aludimos a la tutela de la «verdad personal», puesta de manifiesto a través de la proyección social de la personalidad, no nos referimos a la identidad estática, física, sino a la identidad que denominamos «dinámica», como un complejo conjunto de atributos y calificaciones de la persona. Este es el nuevo interés existencial que tiende a incorporarse a los ordenamientos jurídicos, a través de normas que configuren un derecho subjetivo perfecto o típico ${ }^{10}$.

Nos dice, asimismo, que «[...] la identidad personal [...] que se proyecta socialmente $[. .$.$] es dinámica, se enriquece constantemente, se$ eleva y se degrada, progresa, involuciona, cambia [...] tiene una connotación [...] [con] todo aquello que el ser humano hace en y con su vida $[\ldots] \gg^{11}$. Finalmente, al referirse a la protección del derecho a la identidad, Fernández Sessarego agrega que «[...] la identidad, en cuanto fundamental interés existencial [...], debe protegerse de modo preferente. La vida, la libertad y la identidad conforman una trilogía de intereses que podemos calificar como esenciales entre los esenciales. Por ello, merecen una privilegiada y eficaz tutela jurídica ${ }^{12}$.

La atención de la ciencia jurídica en torno a la identidad personal, como interés existencial a tutelar, se inicia en la década de 1980. La concepción del derecho a la identidad en su doble dimensión es consagrada en diversas constituciones, legislaciones y jurisprudencia que aparecen entre los años ochenta y noventa. Así, el derecho a la identidad es objeto de tutela constitucional y legal en diversos países latinoamericanos, entre ellos el Perú ${ }^{13}$, Ecuador ${ }^{14}$, Paraguay ${ }^{15}$, Bolivia y Venezuela. En lo que respecta a la jurisprudencia, el primer bosquejo de lo que sería luego el derecho a la identidad personal aparece, sustancialmente, como un

8 lbid., pp. 25 y 88.

9 «Laidentidad, como apunta Fromn, es la experienciaque permite a una persona decir 'yo', como 'un centro organizador activo de la estructura de todas mis actividades reales y potenciales'. Yo soy en la medida 'en que vivo, en queestoy interesado, en que tengo relaciones, soy activo y healcanzado una integración entre laaparienciaen relación a [sic] los demás y conmigo mismo ylaesencia demi personalidad'».Fromn, Erich. La rivoluzione della speranza. En Fernández. Op. cit., p.16.

10 Ibid., p. 25.

11 lbid., pp. 87 y 88.

12 lbid., p. 22.

13 Constitución de 1993, artículo 2: «Toda persona tiene derecho: 1. [...] a su identidad».

14 Constitución de 1998, artículo23: «Sin perjuicio de los derechos establecidosenesta Constitución yen los instrumentos internacionales vigentes, el Estado reconocerá y garantizará a las personas los siguientes: [...] 24. El derecho a la identidad, de acuerdo con la ley». Artículo 49: «Los niños y adolescentes gozarán de los derechos comunes al ser humano, además de los específicos de su edad. EI Estado les asegurará y garantizará el derecho [...] a su identidad, nombre y ciudadanía [...]».

15 Constitución de 1992, artículo 25: «Toda persona tiene el derecho a la libre expresión de su personalidad, a la creatividad y a la formación de su propia identidad e imagen [...]».

EL DERECHO A LA PROPIEDAD COMO

DIMENSIÓN DEL DERECHO A LA IDENTIDAD 
aporte de la jurisprudencia italiana. La primera expresión jurisprudencial, pronunciada el 6 de mayo de 1974, reconoce, por primera vez, el derecho a la identidad personal, entendida como la «verdad personal» proyectada socialmente ${ }^{16}$. Asimismo:

[...] la sentencia de la Corte de Casación Italiana, del 22 de junio de 1985, constituye un aporte determinante en el desarrollo jurisprudencial del derecho a la identidad personal, al establecer que [...] la identidad personal integra un bien especial y fundamental de la persona, como es aquél de ver respetado de parte de los terceros su modo de ser en la realidad social, o sea, de que el sujeto vea garantizada la libertad de desarrollar integralmente la propia persona individual, ya sea en comunidad en general como en las comunidades particulares ${ }^{17}$.

En lo que respecta a la violación al derecho a la identidad en su dimensión dinámica, esta se produce cuando se «desfigura» o «deforma» la imagen que uno tiene frente a los demás ${ }^{18}$. Ello se genera por desconocimiento, por falta de reconocimiento o conocimiento erróneo o incompleto de las cualidades de las personas, de sus principales proyecciones y actividades — profesionales y empresariales_-, y de sus principales derechos y activos.

\section{EL DERECHO A LA PROPIEDAD COMO DERECHO FUNDAMENTAL}

El derecho a la propiedad y el derecho a la seguridad jurídica son derechos fundamentales, reconocidos tanto por constituciones y leyes como por tratados y convenios internacionales ${ }^{19}$.

16 «Enestefallosereconoce, por primera vez, el 'derechodecada unoaquenoseledesconozcan suspropias acciones' y también a que 'no se le atribuya la paternidad de acciones que no le son propias'. En suma, a nover'alteradalapropiapersonalidadindividual[...]'.Segúnelpronunciamientojudicial[...]laafirmaciónde la 'verdad personal' constituye lanota conceptual determinantedel derechoala identidad personal [...]. Es decir, se sitúa el problema en el campo del conocimiento y no de la estimación axiológica. [...] La identidad personal tiene que ver con el respeto a la verdad biográfica, por lo que se trata de un acto cognoscitivo, mientrasquelareputaciónconsisteen unactovalorativooaxiológicoformuladoporlosdemás". FERNÁNDEZ. Op. cit., pp. 63 y 66

17 Ibid., p. 100.

18 «Conforme lo apunta Lorenzetti, en Estados Unidos, se arroja una falsa luz en la mirada del público (false light in the public eye). Esto ocurre cuando se distorsiona al ser humano presentándolo con atributos que no le son propios, o cuando se omiten rasgos definitorios de su personalidad, o se atribuyen la paternidad de acciones no propias o se desconocen las propias». LORENZETTI, Ricardo Luis. «Constitucionalización del Derecho civil y derecho a la identidad personal en la doctrina de la Corte Suprema». L.L. 10 de agosto de 1993. Citado en FERRARI, Miriam. El derecho a la identidad personal, naturaleza y tutela jurídica. En: <usuarios.lycos.es/ Miriam Ferrari/doc.html>, p. 2.

19 Así, por ejemplo, el artículo 2 inciso 16) la Constitución Peruana de 1993 señala que toda persona tiene derecho «[...] a la propiedad y a la herencia [...]», lo cual consagra el derecho fundamental a la propiedad como un derecho inherente o consustancial a toda persona humana. El artículo 70, por su parte, señala que «[...] el derecho de propiedad es inviolable. El Estado lo garantiza. Se ejerce en armonía con el bien común y dentro de los límites de ley. A nadie puede privarse de su propiedad sino, exclusivamente, por causa de seguridad nacional o necesidad pública, declarada por ley, y previo pago en efectivo de indemnización justipreciada que incluya compensación por el eventual perjuicio. Hay acción ante el Poder Judicial para contestar el valor de la propiedad que el Estado haya señalado en el procedimiento expropiatorio». Además, entre los instrumentos internacionales ratificados por el Perú que reconocen este derecho, se encuentran el artículo 17 de la Declaración Universal de Derechos Humanos, el artículo VIII de la Declaración Americana de los Derechos y Deberes del Hombre y el artículo 21 de la Convención Americana de Derechos Humanos, que determinan el derecho de toda persona a la propiedad. 
De acuerdo con la CLEP ${ }^{20}$, «[... la propiedad de bienes, ya sea en forma individual o en asociación con otros, es un derecho humano $[\ldots]$.. En relación con los componentes fundamentales de un buen sistema de propiedad, la CLEP considera que:

[...] un sistema de propiedad que funcione plenamente consta de cuatro componentes básicos: un sistema de normas que define el conjunto de derechos y obligaciones entre las personas y los recursos, reflejando la multiplicidad y diversidad de los sistemas de propiedad en todo el mundo; un sistema de gobernabilidad; un mercado en funcionamiento para el intercambio de bienes; y un instrumento de políticas sociales. Cada uno de dichos componentes puede operar en forma disfuncional, volviéndose en contra de los pobres. Cuando el sistema funciona en su totalidad, se convierte en un vehiculo para la inclusión de los pobres en la economía formal y en un mecanismo para ascender socialmente. Cuando hay un mal funcionamiento de la totalidad del sistema o de un único componente, se despoja de oportunidades a las personas pobres, o bien se les discrimina.

$\mathrm{Al}$ referirse al reconocimiento y a la protección de los derechos de propiedad en el sistema jurídico peruano, el ex Defensor del Pueblo en el Perú, Walter Albán Peralta, en un informe presentado ante del Tribunal Constitucional ${ }^{21}$, afirma lo siguiente:

En general, podemos señalar que el derecho a la propiedad se encuentra reconocido dentro del catálogo clásico de libertades o derechos fundamentales, es decir, dentro del núcleo duro o esencial de derechos reconocidos al hombre en las Constituciones de todo Estado moderno, representando un valor ético y político asumido por toda comunidad e implicando un deber de abstención para el Estado y para los particulares referido a no limitar o restringir su ejercicio ${ }^{22}$.

Se establece, además, que:

[...] la Constitución consagra y protege el derecho de propiedad en dos ámbitos: a) el derecho de tener acceso a la propiedad y b) el de propiedad como poder jurídico entre ciudadano y bien, es decir al derecho a disfrutar, disponer y reivindicar sus bienes [...] (tal y como lo señala el art. 923 del Código Civil, al establecer que la propiedad es el poder jurídico que permite usar, disfrutar, disponer y reivindicar un bien). Para

20 CLEP. Op. cit., p. 7.

21 ALBÁN, Walter.Informe(amicuscuriae)presentadoantealTribunalConstitucionalporelDefensordeIPueblo el 13dejunio de 2003, pp.17 y 18. El informefue presentadocon motivo de laacción de inconstitucionalidad interpuesta por el Colegio de Notarios contra los artículos 7 y 13 de la ley 27755, que crea el Registro de Predios, publicada el 15 de junio de 2002 en el diario oficial El Peruano.

22 Con relaciónalaprotecciónalderechodepropiedad,conferidaporelartículo2inciso16delaConstitución, Albán cita a Enrique Bernales Ballesteros, quien señala que «[...] la norma [...] resulta muy importante, porque formula una aproximación directa al derecho de acceso a la propiedad y a la protección jurídica que sobre ella recae. Desde luego, aquí se consagra una posibilidad abierta a todos; un derecho formal que impide prohibiciones en el acceso a la propiedad y en la posibilidad de ser propietario". BERNALES Ballesteros, Enrique. La Constitución de 1993. Análisis comparado. Lima: ICS Editores, 1996, pp. 93 y 96. En Albán. Op. cit., p. 17.

EL DERECHO A LA PROPIEDAD COMO

DIMENSIÓN DEL DERECHO A LA IDENTIDAD 
garantizar el pleno ejercicio del derecho de propiedad como poder jurídico, el Estado crea mecanismos como los de los Registros Públicos, cuya finalidad es brindar seguridad jurídica, a través de la publicidad que otorga y que, a su vez, permite que el derecho inscrito sea oponible. Es decir, que el resto de la sociedad pueda conocer el derecho del que han sido excluidos y que, de dicha manera, el «propietario» pueda ejercer plenamente los atributos inherentes a su derecho de propiedad sobre bienes inmuebles ${ }^{23}$.

Por otro lado, al referirse al derecho a la seguridad jurídica, Albán ${ }^{24}$ señala que «[...] la seguridad jurídica es un principio constitucional por cuanto, si bien la Constitución no la consagra explícitamente, como sí lo hace la española, por ejemplo ${ }^{25}$, sí reconoce derechos en los que se encuentra implícitamente recogido dicho principio, como en los artículos $2^{\mathrm{o}}$ inciso 24 , literales a) y d) ${ }^{26}, 51^{\mathrm{0} 27}, 62^{\mathrm{o} 28}$, entre otros». Señala, asimismo, que «[...] el Tribunal ya ha manifestado en su jurisprudencia que la seguridad jurídica es un principio[...] $»^{29}$. En el mismo sentido de la jurisprudencia peruana, encontramos que la española establece que «[...] la seguridad jurídica es suma de certeza y legalidad, jerarquía y publicidad normativa, irretroactividad de lo no favorable, interdicción de la arbitrariedad [...]. La seguridad jurídica es la suma de estos principios, equilibrada de tal suerte que permita promover, en el orden jurídico, la justicia y la igualdad, en libertad $»^{30}$. Además, nos dice que «[...] este principio garantiza la confianza que los ciudadanos pueden tener en la

23 lbid., pp. 17 y 18

24 lbid., pp. 19 y 20.

25 Artículo 9.3. de la Constitución Española: «La Constitución garantiza el principio de legalidad, la jerarquía normativa, la publicidad de las normas, la irretroactividad de las disposiciones sancionadoras no favorables o restrictivas de derechos individuales, la seguridad jurídica, la responsabilidad y la interdicción de la arbitrariedad de los poderes públicos». En AlBán. Op. cit., p.19.

26 Artículo 2, inciso 24. Toda persona tiende derecho «[...] a la libertad y a la seguridad personales. En consecuencia: a. Nadie está obligado a hacer lo que la ley no manda, ni impedido de hacer lo que ella no prohíbe. d. Nadie será procesado ni condenado por acto u omisión que al tiempo de cometerse no esté previamente calificado en la ley, de manera expresa e inequívoca, como infracción punible; ni sancionado con pena no prevista en la ley». Ibid.

27 Artículo 51: «La Constitución prevalece sobre toda norma legal; la ley, sobre las normas de inferior jerarquía, y así sucesivamente. La publicidad es esencial para la vigencia de toda norma del Estado». Ibid.

28 Artículo 62: «La libertad de contratar garantiza que las partes pueden pactar válidamente según las normas vigentes al tiempo del contrato. Los términos contractuales no pueden ser modificados por leyes u otras disposiciones de cualquier clase [...]». Ibid.

29 En los puntos 13 y 35 de los fundamentos de la sentencia recaída en el expediente $\mathrm{N}^{\circ}$ 010-2002-Al/TC, el tribunal nos dice lo siguiente: «[...] esta teoría se sustenta en la necesidad de preservar uno de los fines básicos del derecho: la seguridad jurídica [...]». El Tribunal, por lo demás, enfatiza que el fundamento y la legitimidad de uso de este tipo de sentencias radica en el principio de conservación de la ley y en la exigencia de una interpretación conforme a la Constitución, a fin de no lesionar el principio básico de la primacía constitucional; además, se deberá tener en cuenta el criterio jurídico y político de evitar, en lo posible, la eliminación de disposiciones legales, para no propender a la creación de vacíos normativos que puedan afectar negativamente a la sociedad, con la consiguiente violación de la seguridad jurídica. En ALBÁN. Op. cit., p. 20. Por otro lado, en el punto 17 de los fundamentos de la sentencia recaída en el expediente $\mathrm{N}^{\circ} 009$ 2001-Al/TC, se afirma lo siguiente: «A juicio del Tribunal, es lícito que el legislador pueda modificar el sistema normativo. Sin embargo, debe protegerse también la confianza de los ciudadanos frente al cambio brusco, irrazonable o arbitrario de la legislación. Ciertamente, no se garantiza un régimen de derechos adquiridos - con excepción, naturalmente, de los previstos en la Constitución- sino fundamentalmente, el derecho a que no se cambie las reglas de juego abruptamente. En consecuencia, cuando cambia la legislación, y de por medio se encuentra comprometido el ejercicio de determinados derechos fundamentales, todo cambio sólo podrá ser válido si es que, además, se encuentra conforme con el principio de seguridad jurídica [...]". Ibid.

30 STC 27/1981, FJ 10․ RuBio LloRENTE, Francisco. Derechos fundamentales y principios constitucionales (doctrina jurisprudencia). Barcelona: Ariel Derecho, 1995, p. 67. En AlBáN. Op. cit., p. 20. 
observancia y el respeto de las situaciones derivadas de la aplicación de normas válidas y vigentes» ${ }^{31}$.

Al referirse al reconocimiento del derecho a la propiedad, Hernando de Soto señala que:

[...] no existe en el mundo constitución nacional que no reconozca el derecho universal de acceso a la propiedad y hay numerosos convenios internacionales que lo ratifican. [Además] hay programas para dotar a los pobres de propiedad en casi todos los países en vías de desarrollo y en los que salen del comunismo [...]. Hoy [...] el acceso a la propiedad es considerado consubstancial a los derechos fundamentales de la humanidad. Un amplio espectro de tratados internacionales contemporáneos —desde la Declaración Universal de los Derechos del Hombre, 1948, y el catecismo de la Iglesia Católica, hasta el Convenio $\mathrm{N}^{\circ} 169$ de la Organización Internacional del Trabajo sobre Pueblos Indígenas y Tribales, 1989— insiste en la propiedad como un derecho humano básico y permanente $[\ldots]^{32}$.

Lamentablemente, no obstante el reconocimiento universal antes señalado, la gran mayoría de las familias pobres en el mundo no ha logrado obtener el reconocimiento legal de los derechos de propiedad sobre sus tierras y edificaciones. Como consecuencia, para usarlos, transferirlos, explotarlos y protegerlos, los titulares de estos activos deben recurrir a una serie de prácticas y arreglos extralegales, cuya vigencia, en la mayoría de casos, no puede ser exigida más allá de los límites territoriales de la comunidad. Como consecuencia, dichos titulares carecen de los mecanismos legales necesarios para defender sus inmuebles contra terceros cuyos derechos estuviesen amparados por títulos de propiedad y concesiones debidamente inscritos en los registros públicos y por mapas que establecen con precisión y con coordenadas universales su ubicación y linderos. Esta situación no solo les impide acceder a derechos de propiedad seguros y ejecutables, sino también a todos los beneficios que brinda un sistema legal moderno e inclusivo.

Al reflexionar sobre el fenómeno de la exclusión, no podemos dejar de dirigir nuestra mirada a las comunidades indígenas, que, sin lugar a dudas, encabezan la lista de los excluidos. En efecto, los sistemas jurídicos alrededor del mundo no han cumplido con proporcionarles los mecanismos legales necesarios para garantizar la propiedad sobre sus territorios y para facilitarles el tránsito hacia una economía y un Estado de derecho genuinamente inclusivos. Es más, la mayoría de países en desarrollo no han sido capaces de construir un puente institucional que permita establecer un punto de encuentro entre las normas y autoridades de estas comunidades y aquellas imperantes en el sistema estatutario vigente.

EL DERECHO A LA PROPIEDAD COMO

DIMENSIÓN DEL DERECHO A LA IDENTIDAD 
Estas son algunas de las consecuencias resultantes de la ausencia de mecanismos legales que garanticen el acceso a la propiedad y a la seguridad jurídica: no es posible acceder a información veraz y actualizada sobre predios y empresas y sobre sus titulares, lo cual dificulta, entre otros, el planeamiento urbano, la recaudación de impuestos, el control del pago de servicios públicos y del cumplimiento de una serie de obligaciones. También impide la formulación de políticas y estrategias eficaces para garantizar la seguridad ciudadana, prevenir o disminuir los riesgos asociados a desastres naturales y armonizar la protección de los derechos de propiedad, la seguridad de las inversiones, el cuidado del medio ambiente y el manejo de los recursos naturales.

\section{LAS REFORMAS HACIA LA INCLUSIÓN}

Para enfrentar los actuales retos, se requiere de «[...] soluciones integrales y efectivas, lo cual exige, a su vez, reformas comprensivas y de largo alcance que contribuyan a crear un sistema legal que facilite la protección y capitalización de los principales activos de las grandes mayorías, tradicionalmente excluidas del mundo formal $»^{33}$. Dichas reformas deben estar orientadas a facilitar no solo la formalización de los activos extralegales, sino también su capitalización, y en consecuencia brindar a sus propietarios los mecanismos necesarios para «añadir una dimensión económica [a sus activos] que les permita —si así lo quieren - utilizar la representación legal de sus propiedades no sólo para proteger sus derechos, sino también para generar múltiples funciones económicas que van más allá de la sola posesión y vincular sus activos al mercado y al mundo financiero ${ }^{34}$.

En relación con el empoderamiento legal de los pobres, la CLEP está convencida de que los cuatro mil millones de excluidos en el mundo poseen capacidades y activos importantes. En consecuencia, «[...] si se reforman los Estados y las leyes de modo que se brinde adecuado reconocimiento a los pobres, si se logra que el sistema legal funcione para todos, aquellos que están excluidos comenzarán rápidamente a trascender sus circunstancias actuales y contribuirán a la solución de problemas económicos y sociales que de otro modo continuarían siendo crónicos» ${ }^{35}$.

Desde nuestro punto de vista, el principal reto de la reforma consiste en construir los cimientos que permitan el tránsito hacia un sistema legal que garantice a las mayorías el goce de los principales atributos de la propiedad. Tales atributos, de manera sucinta, se detallan en el siguiente recuadro. 


\section{Principales atributos de la propiedad}

1. «Fijar el potencial de los activos: representando por escrito —en títulos, contratos u otros documentos- las características más relevantes de los activos. Esta representación escrita asegura los intereses del propietario y de terceras partes, estableciendo las reglas y mecanismos aplicables a las obligaciones involucradas.

2. Integrar información dispersa: juntando los acuerdos extralegales dispersos sobre la propiedad en un sistema único, consistente y sistematizado de representaciones que opera dentro de un gran consenso nacional. Esto permite actuar en mercados expandidos bajo un solo sistema legal y con títulos y registros estandarizados.

3. Hacer fungibles a los activos: representándolos de manera tal que puedan ser fácilmente movilizados, resulten más accesibles al mercado y tengan mayores funciones. Ello implica, entre otros, estandarizar las definiciones y representaciones de los activos para facilitar la medición de sus atributos, su combinación para alcanzar mayor valor, su división en acciones, la valuación objetiva de las acciones y el suministro de un historial de transacciones sobre éstas.

4. Hacer responsables a las personas: extendiendo la protección del sistema legal y el imperio de la ley a los derechos de propiedad de las mayorías, que antes sólo eran protegidos por prácticas y acuerdos extralegales, vigentes únicamente al interior de comunidades y grupos locales.

5. Poner a las personas en red: creando el marco institucional que permita conectar, de manera simplificada y poco onerosa, a todos los activos y sus titulares con un mercado expandido en el que puedan combinarse con otros agentes para múltiples fines y desarrollo de productos.

6. Proteger las transacciones: asegurando no sólo la propiedad de los activos sino su utilización económica y su mayor valor de intercambio, a través de mecanismos que brinden al mercado información confiable, accesible y actualizada sobre la ruta que han seguido sus diversas transacciones y representaciones y que permitan la creación de una cadena de buena fe y confianza para compradores, inversionistas y terceros en general $»^{36}$.

En tal sentido, los principales componentes de la agenda para una reforma inclusiva son los siguientes: 
1. Mecanismos simplificados y de bajo costo para garantizar el derecho a la identidad. El primer paso hacia la inclusión es establecer mecanismos simplificados y de bajo costo para garantizar el derecho a la identidad en su doble dimensión; ello permitiría que las mayorías pobres puedan no solo acreditar su existencia legal, sino también incorporar sus principales activos a una economía moderna e inclusiva.

Respecto de la llamada dimensión estática del derecho a la identidad, la falta de documentación constituye un gran obstáculo tanto para acreditar la existencia legal de una persona $-\mathrm{y}$ ser reconocido como titular de una serie de derechos civiles y políticos-, como para lograr el reconocimiento legal de sus tierras, edificaciones y negocios. La realidad es que un alto porcentaje de ciudadanos a nivel mundial carece de documentos de identidad o posee un documento inválido o defectuoso. Asimismo, en muchos casos, los procedimientos para registrar nacimientos y obtener documentos de identidad son complejos y onerosos. Además, muchos de los sistemas que manejan los registros de identidad y capacidad civil carecen de mecanismos para garantizar la seguridad de las inscripciones y facilitar el acceso a la información registral. Los principales problemas para identificar a las personas pueden apreciarse en el siguiente cuadro ${ }^{37}$.

\section{Principales obstáculos para identificar a las personas}

— Procedimientos complejos y costosos para registrar el estado civil de las personas (nacimientos, defunciones, matrimonios, divorcios, etcétera) y para obtener un documento de identidad. En algunos países, incluso, se requiere de procedimientos judiciales para simples trámites administrativos.

— Falta de estandarización en normas, procedimientos y técnicas registrales.

- Carencia de coordinación entre las diversas entidades públicas encargadas de registrar el estado civil de las personas y de identificarlas.

— Existencia de un sin número de documentos de identidad para diversos fines (certificados de nacimiento, documentos electorales, carnés de seguridad social, documentos de identificación tributaria, documentos nacionales de identidad, etcétera) y demasiadas entidades públicas involucradas en su emisión.

37 Como consecuencia de dichos obstáculos, en el mundo una cantidad elevada de personas aún carece de identificación legal. De acuerdo con data de UNICEF, un tercio de los recién nacidos a nivel mundial no se registran - la cifra equivale a unos 50 millones de personas-; en el caso del Asia, el porcentaje supera el 60\% (UnICEF, 2006). Por otro lado, menos del 30\% del total de los países miembros de la Organización Mundial de la Salud cuenta con un sistema de identificación y registro que cubra por lo menos al $90 \%$ de la población (UNICEF, 2006); y en América Latina y el Caribe un 15\% de los niños menores de 5 años carece de certificados de nacimiento (UNICEF, 2001) —en el caso de Haití, más del $60 \%$ carece de dichos documentos(Asociación de Seguros de Haití, 2004). 
— Dificultades para acceder a la información y archivos de los registros de estado civil. En algunos casos, la información ni siquiera es pública.

- La mayoría de sistemas de registro e identificación de personas se construyen sin tener en cuenta el derecho consuetudinario y las prácticas extralegales que son utilizadas y reconocidas por la mayoría de ciudadanos para identificar a las personas.

— Documentos de identidad inválidos o defectuosos — por errores, falsificación o falta de registro-.

— Sistemas de registro inseguros. Muchos registros de identificación y estado civil carecen de mecanismos para prevenir fraudes, duplicidad de registros - personas que son registradas más de una vez con el mismo o con diferente nombre-, deterioro, pérdida o destrucción de información y de archivos registrales.

- Carencia de información relevante en documentos de identidad. Muchos documentos de identidad carecen de información relevante para identificar a personas que tienen los mismos nombres y apellidos (homonimia) - por ejemplo, no cuentan con fotografías o con información sobre características físicas y estado civil-.

En consecuencia, las reformas en materia de identificación de las personas deben estar dirigidas a brindar a los ciudadanos mecanismos simplificados y de bajo costo para registrar nacimientos y obtener documentos de identidad, así como a establecer sistemas seguros y accesibles de registro.

En el caso del Perú, por ejemplo, con la promulgación de la Constitución de 1993 (artículos 177 y 183), se creó el Registro Nacional de Identificación y Estado Civil - ReNIEC, como organismo autónomo, con personería jurídica de derecho público interno, responsable de organizar y de mantener el Registro Único de Identificación de Personas Naturales, adoptar mecanismos que garanticen la seguridad en la emisión de los documentos de identidad, inscribir hechos y actos relativos a la capacidad y el estado civil de las personas, y asegurar la confiabilidad de la información que resulta de la inscripción ${ }^{38}$. El Documento

38 RENIECes partedel sistemaelectoral peruanoyestáreguladopor laLey 26497 de 1995. Entresus principales funciones, figuran las siguientes: planear, organizar, dirigir, normar y racionalizar las inscripciones de su competencia;registrarlosnacimientos, matrimonios, divorcios, defuncionesydemásactosquemodifiquen elestadocivildelaspersonasyemitirlasconstancias deinscripcióncorrespondientes;emitireldocumento únicoqueacreditalaidentidaddelaspersonasymantenerelregistrocorrespondiente; prepararymantener actualizadoelpadrónelectoralencoordinaciónconlaOficinaNacionaldeProcesosElectorales;yproporcionar al Jurado Nacional de Elecciones y a la Oficina Nacional de Procesos Electorales la información necesaria paraelcumplimientodesusfunciones. Hoy RENIEcesconsideradounodelosregistrosdeidentidadyestado civil más modernos y avanzados de Latinoamérica.

EL DERECHO A LA PROPIEDAD COMO

DIMENSIÓN DEL DERECHO A LA IDENTIDAD 
Nacional de Identidad (DNI) que emite RENIEC ha devenido en el principal documento de identificación para los peruanos, e incluso reemplazó progresivamente a las actas de nacimiento. Sin embargo, es importante señalar que, no obstante las reformas y las campañas de «restitución del derecho a la identidad» desplegadas por el RENIEC durante la última década, de acuerdo con el último Censo Nacional de Población por lo menos medio millón de peruanos mayores de 18 años carecen de DNI y más de un cuarto de millón no cuenta con certificado de nacimiento. Desgraciadamente, muchos de los indocumentados son miembros de comunidades campesinas y nativas, y habitantes de las zonas más deprimidas del país ${ }^{39}$. La falta de identificación se debe, por un lado, a que los procedimientos para registrar nacimientos y para obtener un DNI siguen siendo complejos y costosos para los peruanos más pobres; y, por otro, a que aún está pendiente la reconstrucción de buena parte de los registros de estado civil destruidos como resultado de desastres naturales y de la violencia política en el Perú (período 1980-1995). A la fecha, no existen estadísticas oficiales sobre la cantidad de registros de estado civil pendientes de reconstrucción; sin embargo, sí se conoce que 61\% de las víctimas de violencia política en el país carece de $\mathrm{DNI}^{40}$.

2. Mecanismos simplificados y poco onerosos para inscribir personería jurídica y registrar representación legal. En el caso de las comunidades indígenas y de otras formas asociativas de tenencia y explotación de la tierra, se requiere de mecanismos simplificados y poco onerosos para inscribir su personería jurídica, acreditar los poderes y mandatos de sus representantes legales y documentar sus estatutos.

En muchos casos, la complejidad y la onerosidad de los procedimientos registrales antes mencionados ha constituido un gran obstáculo para que tanto comunidades como empresas campesinas asociativas puedan formalizar sus derechos de propiedad sobre la tierra y ejercitar derechos fundamentales. Así, por ejemplo, en el caso del Perú, a finales de los años ochenta, regularizar la inscripción de los representantes legales de una comunidad campesina podía tomar entre cinco y seis décadas ${ }^{41}$. Durante la década de 1990, se promulgó una serie de normas dirigidas a facilitar la inscripción de la personalidad jurídica de comunidades, empresas campesinas y cooperativas, así como el registro de sus estatutos y representantes legales. Respecto de la representación legal, se establecieron, asimismo, mecanismos para regularizar los actos y contratos en los que hubiesen intervenido representantes cuyos mandatos carecían de inscripción en los registros públicos. No obstante estas reformas, los

39 A partir de las campañas de tramitación del DNI realizadas en los lugares más alejados del país, RENIEC ha podido comprobar que un promedio de 30 a $35 \%$ de peruanos no puede obtener un DNI por errores en sus actas de nacimiento (<http://www.mef.gob.pe/DNPP/PpR/PPSTR/Acceso.población.identidad.pdf/>).

40 SegúnlaDefensoríadelPueblo,estacifracorrespondealascincozonassupervisadas(Huánuco,Ayacucho, Puno,Cuscoy Apurímac), dondelaviolenciapolíticaestuvomásacentuada. DeclaracionesdeSusanaSilva, defensora adjunta para la administración estatal. El Peruano, 16 de octubre de 2008, Actualidad, p. 21.

41 Este fue, por ejemplo, el caso de las comunidades campesinas San Juan de Tantarache (de 1938 a 1991) y San Pedro de Huancayre (de 1926 a 1991), ambas situadas en el Departamento de Lima. 
procedimientos registrales son aún costosos para muchas comunidades y empresas campesinas, por lo cual es frecuente que los mandatos de sus representantes legales permanezcan sin registro; por ende, los actos en que estos intervienen no son exigibles frente a terceras personas. Según estudios recientes, únicamente $20 \%$ de las comunidades registra los mandatos de sus representantes legales, y no más del $60 \%$ inscribe sus estatutos ${ }^{42}$.

\section{Mecanismos y procedimientos simplificados y de bajo costo para formalizar} diversos tipos de extralegalidad sobre activos prediales, así como para estimular su permanencia en legalidad. Resulta indispensable brindar mecanismos que permitan la formalización de todo tipo de tierra, sea esta urbana, rural o forestal. Por lo tanto, para asegurar el éxito de la reforma, se requiere contar con un diagnóstico previo, integral y comprensivo de todos los tipos de extralegalidad predial existentes en cada país. Se requiere también identificar los principales obstáculos que impiden o dificultan su regularización, así como las principales normas y prácticas extralegales utilizadas por la mayoría de la población para asignar y proteger derechos sobre tierras y edificaciones, y para acreditar las transacciones que se realizan sobre estas.

\section{Un nuevo enfoque de la extralegalidad}

Un diagnóstico comprensivo requiere un nuevo enfoque de la extralegalidad, que permita ampliar el enfoque tradicional sobre la materia: «[...] Tradicionalmente, se pensaba que la extralegalidad solo afectaba a 'los marginales', a quienes habían invadido terrenos de propiedad ajena y a quienes habitaban tugurios. La mirada no alcanzaba al gran universo de titulares, quienes, a pesar de haber adquirido legalmente sus predios y haber invertido en ellos, no han podido mantenerse en la formalidad debido a los [...] obstáculos y costos impuestos por el ordenamiento jurídico vigente, situación por la cual se ven impedidos de gozar a plenitud de los atributos inherentes al derecho de propiedad» . «Tampoco se vinculaba el universo extralegal a los propietarios con derecho inscrito que no gozan de plena seguridad legal por deficiencias del sistema registral —que los expone a riesgos de superposición de áreas de predios inscritos, multiplicidad de titulares, falsificación de documentos y suplantación de propietarios- - La mirada tampoco se acercaba a los titulares que, debido a $[\ldots]$ injustificadas prohibiciones y limitaciones, no pueden intercambiar sus activos prediales en el mercado ni darles su máximo valor de uso. Fue a partir de una nueva y comprensiva mirada al tema de la extralegalidad que pudimos apreciar que, tanto en el Perú como en la gran mayoría de países en desarrollo, esta abarcaba a porcentajes significativos de predios, en diversos grados y niveles, y

EL DERECHO A LA PROPIEDAD COMO

DIMENSIÓN DEL DERECHO A LA IDENTIDAD 
que aquéllos [sic] debían ser identificados y clasificados en función del grado y origen de la extralegalidad. Sólo a partir de dicho diagnóstico es posible diseñar una reforma dirigida a la formalización y capitalización del universo de activos extralegales» ${ }^{43}$.

4. Mecanismos para garantizar el reconocimiento y la incorporación de las normas y prácticas extralegales que la mayoría de la población aplica y respeta. Se trata de reconocer e incorporar al sistema legal aquellas normas y prácticas de la mayoría de la población para asignar y proteger derechos sobre activos prediales y para documentar las transacciones sobre estos.

Cuando Hernando de Soto describe el proceso de diseño de la reforma para posibilitar el tránsito a un sistema de propiedad moderno e inclusivo, enfatiza que «[...] la ley no es algo que se pueda inventar en una universidad; la ley es algo que se descubre. Los pobres ya han realizado acuerdos recíprocos, es decir, contratos sociales, y lo que se debe hacer es conferir un estándar profesional a estos contratos con el fin de crear un sistema legal reconocido y respetado por todos» ${ }^{44}$.

Este tipo de reformas reviste particular importancia en relación con las comunidades indígenas. Al referirse al reconocimiento del derecho consuetudinario de las comunidades, Raquel Yrigoyen afirma que:

[...] los estudios empíricos sobre los sistemas normativos indígenas dan cuenta de: 1) que no solo se trata de prácticas aisladas, sino que tienen un eje cultural que las articula a modo de sistema y tienen sistemas de normas, autoridades y procedimientos por los cuales regulan su vida social, resuelven conflictos y organizan el orden interno $[\ldots]$ y, 2) su enorme capacidad de adaptación y cambio, pues [...] deben responder a necesidades y demandas sociales cambiantes $[\ldots]$.

Señala, asimismo, que:

[...] la posibilidad de garantizar la seguridad jurídica a todos los individuos y grupos dentro de un Estado donde hay diversidad cultural, es, justamente, permitiendo la vigencia de los diversos sistemas normativos, con reglas para las situaciones de interculturalidad. Así, todo individuo y grupo tendrá la certeza de que podrá ser juzgado [...] bajo las reglas que conoce y en cuyo marco se ha socializado, respetando a su vez la diversidad cultural ${ }^{45}$.

Las principales reformas dirigidas al reconocimiento de la identidad cultural, al derecho consuetudinario y a las autoridades de estas comunidades se iniciaron a principios de los años noventa, con su incorporación

43 Delgado. «La formalización de la propiedad predial en el Perú». Op. cit., p. 63.

44 CLEP. Op. cit., 2008, contratapa del libro.

45 Yrigoyen Fajardo, Raquel. Pautas de coordinación entre el Derecho indígena y el Derecho estatal. Guatemala: Fundación Myrna Mack, 1999, pp. 8-9. 
en convenios internacionales ${ }^{46}$ y en una serie de constituciones. Así, por ejemplo, los países latinoamericanos cuyas constituciones incorporaron este reconocimiento son el Perú ${ }^{47}$, Bolivia, Colombia, Ecuador, México, Nicaragua, Paraguay y Venezuela. Dichas constituciones reconocen expresamente el derecho de las comunidades indígenas a la identidad cultural y a resolver conflictos dentro de su ámbito territorial, de conformidad con el derecho consuetudinario, siempre que no se violen derechos fundamentales ${ }^{48}$. No obstante, debemos ser conscientes de que la mayoría de países de Latinoamérica aún no cuenta con legislaciones adecuadas, que les permita hacer realidad el reconocimiento constitucional antes referido.

5. Mecanismos que permitan a sus titulares elegir el tipo de tenencia y explotación de la tierra que más convenga a sus intereses y necesidades, y que faciliten la utilización económica de los activos inmobiliarios. Ello significa que debe evitarse la imposición de un determinado modelo de tenencia y explotación de la tierra — sea este individual o colectivo-. Por el contrario, el sistema legal debe brindar a todos los titulares la posibilidad de optar por el sistema de propiedad que sea más apropiado a su realidad y a los usos asignados a cada tipo de tierra. Por otro lado, resulta fundamental establecer normas claras respecto de los atributos y limitaciones de los diversos títulos que se otorgan sobre tierras y edificaciones, de forma tal que las reglas de juego estén adecuadamente definidas, tanto para los titulares de dichos activos como para quienes participan en transacciones sobre estos. Asimismo, es recomendable que se eliminen las restricciones y prohibiciones injustificadas para transferir, gravar, arrendar y dar un uso económico a los derechos sobre predios. Así, por ejemplo, es usual encontrar estas limitaciones en títulos otorgados por diversos Estados a beneficiarios de programas de vivienda pública, de formalización de la propiedad y de reforma agraria. Ha quedado demostrado, sin embargo, que, en la gran mayoría de casos, dichas prohibiciones no han impedido ni el arrendamiento ni las sucesivas transferencias de propiedad sobre dichos inmuebles, hecho que ha generado más situaciones de extralegalidad sobre la propiedad predial.

46 Elconvenio internacional más relevanteenestamateriaes el Convenio 169 de la OIT sobre los Derechos de las Pueblos Indígenas y Tribales en Países Independientes, adoptado en 1989 y en vigencia internacional desde1991. Elconvenio(artículos8y9)establecelaobligacióndelosEstadosdepermitiralascomunidades conservarsuscostumbreseinstitucionessiemprequeestasnoviolenderechosfundamentales.Alafecha,el conveniohasidoratificadoporveintepaíses,catorcedeloscualessonlatinoamericanos,entreelloselPerú desde 1994

47 El artículo 89 de la Constitución Peruana de 1993 establece que «El Estado respeta la identidad cultural de las Comunidades Campesinas y Nativas». Además, de acuerdo con el artículo 149, «Las autoridades de las Comunidades Campesinas y Nativas, con el apoyo de las Rondas Campesinas, pueden ejercer las funciones jurisdiccionales dentrodesuámbito territorial deconformidad conelderechoconsuetudinario, siempre[que]noviolen losderechosfundamentalesdelapersona[...]".Dispone, además,quecorresponde a la ley establecer «[...]lasformas decoordinación de dichajurisdicciónespecialcon los JuzgadosdePazy con la demás instancias del Poder Judicial».

48 «En la última década, varios países latinoamericanos, como Colombia (1991), Perú (1993), Bolivia (1994), Ecuador (1998), han reconocido constitucionalmente el carácter pluricultural de la Nación y el Estado [...] también han reconocido la existencia y derechos de los pueblos y comunidades indígenas, oficializando sus idiomas, y promoviendo el respeto y desarrollo de sus culturas, formas de organización social, sus costumbres, trajes, religión,etc.Igualmente, hanreconocidoelderechoindígenaoconsuetudinario, afinde iniciarprocesosdecoordinaciónocompatibilizaciónentreambossistemas,desdeunaperspectivadediálogo democrático y no de represión». Yrigoyen. Op. cit., p. 9.

EL DERECHO A LA PROPIEDAD COMO

DIMENSIÓN DEL DERECHO A LA IDENTIDAD 
6. Mecanismos efectivos de solución de disputas. Resulta indispensable diseñar mecanismos simplificados y efectivos para solucionar las disputas que pudieran originarse con motivo de la asignación y transferencia de derechos de propiedad, que son bastante frecuentes durante procesos de formalización. Al respecto, existen dos tipos de mecanismos novedosos y efectivos que se han empleado durante los últimos años. Por un lado, tenemos a los mecanismos alternativos de solución de conflictos, entre los que destaca la conciliación; por otro, están los tribunales administrativos creados para solucionar las controversias que se suscitan entre el Estado y los particulares a partir de procesos de formalización y registro de derechos de propiedad sobre inmuebles ${ }^{49}$. En lo que respecta a la vía judicial, los esfuerzos deberían orientarse a fortalecer a la justicia de paz, cuyos jueces desempeñan un rol fundamental en la solución de una serie de controversias, entre ellas las que se originan en torno a los derechos de propiedad ${ }^{50}$.

7. Un sistema registral pro-activo, moderno, seguro y de fácil acceso. Nos referimos a la creación y a la puesta en marcha de un sistema que pueda ser extendido a todo el país en forma progresiva, y que cuente con procedimientos simplificados y de bajo costo para estimular no solo la primera inscripción de los derechos sobre activos prediales, sino también el registro de los futuros actos y transacciones que se realicen sobre estos.

El Perú ofrece el mejor ejemplo del sistema registral propuesto. Nos referimos al sistema del nuevo registro de la propiedad predial, denominado Registro Predial (RP), creado a finales de los años ochenta con el fin de registrar predios en pueblos jóvenes y urbanizaciones populares a nivel nacional, y como registro paralelo al registro tradicional existent $\mathrm{e}^{51}$ : «El $\mathrm{RP}$ fue dotado de un nuevo sistema y procedimientos registrales rápidos, simplificados, seguros y poco onerosos, así como de una serie de mecanismos para estimular no solo el acceso sino también la permanencia en la formalidad.$^{52}$ Podemos sintetizar las características relevantes de este sistema en el siguiente cuadro.

49 Así, por ejemplo, en el caso peruano, al crearse el sistema de formalización de la propiedad a cargo de CofoprI (decreto legislativo 803, 1996), se establecieron tres mecanismos de solución de conflictos: un sistemadeconciliación yun TribunalAdministrativodelaPropiedad, acargodeCofoPRI,yelSistemaArbitral de la Propiedad.

50 Este es, por ejemplo, el caso del Perú, donde el $27 \%$ de controversias que se presentan ante los jueces de paz se relacionan con derechos de propiedad. Ardito, Wilfredo y David Lovatón. Justicia de paz. Nuevas tendencias y tareas pendientes. Lima: Instituto de Defensa Legal, 2002, p. 17. Citado en FAúndez, Julio. NonState Justice Systems in Latin America. Case Studies: Peru and Colombia. Coventry: University of Warwick, 2002, p. 25.

51 Delgado. «La formalización de la propiedad predial en el Perú». Op. cit., p. 65.

52 «EIRP se creóa finales de 1988 (decretos legislativos 495 y 496) como institución pública descentralizada, con autonomía registral, técnica, administrativa y económica, para registrar predios en pueblos jóvenes y urbanizacionespopularesanivelnacional[...]".Inicióactividadesenenerode1990.(RegistrodelaPropiedad Inmueble - RPI). 


\section{Principales características del sistema del Registro Predial}

\section{(según sus normas de creación) ${ }^{53}$}

— «[...] Tiene un sistema de naturaleza 'pro-activa' que le permite realizar las actividades que no son usuales respecto a una oficina pública tradicional. Desarrolla campañas de comunicación para diseminar los beneficios de la formalización y registro de los activos prediales [...]. Realiza actividades de formalización y registro con la participación de beneficiarios y principales actores involucrados y traslada al personal del registro al campo para realizar actividades de verificación técnica y legal.

- Cuenta con mecanismos para adaptar la normatividad vigente a las nuevas circunstancias que se [...] presentan durante el proceso de formalización y registro.

— Tiene una estructura descentralizada y desconcentrada [...] [con] una oficina de Registro Predial en cada [...] región del país, cada una de las cuales son independientes entre sí y gozan de autonomía registral, económica y administrativa ${ }^{54}$. Su organización fue diseñada tomando como base el modelo de organización de una empresa privada, con el objetivo que los servicios registrales pudieran funcionar con el mínimo de personal necesario ${ }^{55}$. Además, incorpora a representantes de usuarios en la dirección de la institución ${ }^{56}$.

- Cuenta con procedimientos registrales descentralizados, simplificados y de bajo costo, y elimina trámites redundantes e innecesarios.

- Facilita el acceso al registro al posibilitar el uso de formularios registrales firmados por abogados o por notarios, los que [...] brindan igual o mayor seguridad a los actos registrados [...] [y] son estandarizados, fáciles de entender y llenar, por lo cual disminuyen los costos de transacción y facilitan una formalización masiva ${ }^{57}$.

53 Delgado. «La formalización de la propiedad predial en el Perú». Op. cit., pp. 65-66.

54 Afinalesdelosañosochenta,latomadedecisionesenelsistematradicionalderegistro(OficinaNacionalde losRegistros Públicos-ONARP)implicabapasarportresinstancias:elregistrador,laComisiónFacultativa y la Junta de Vigilancia, las dos últimas centralizadas en Lima. Por lotanto, entodas las apelaciones debían intervenir,ensegundainstancia,eldirectorgeneralejecutivo,eldirectorgeneralregistralyeldirectorgeneral de asesoría jurídica de la ONARP; y, en tercera instancia, el ministro de Justicia, el fiscal de la nación, el decano delColegio de Abogados, el decano del Colegio de Notarios-osus representantes-, yeljefedela ONARP, entre otros.

55De acuerdo con sus normas de creación, la estructura orgánica del RP era la siguiente: directorio y director ejecutivoogerentegeneral(altadirección)yregistradores(oficinasregistraleszonales). Elregistrotradicional, en cambio, presentaba una estructura orgánica centralizada y concentrada en la ONARP; sus oficinas registralesnoposeíanautonomíaregistral,económicaniadministrativa, por loquelamayoríadedecisiones en esos aspectos se tomaba en Lima.

56 Originalmente,eneldirectoriodelRPestabanrepresentadoslosusuarios(pueblosjóvenesyurbanizaciones populares)ylasinstitucionesdirectamenteinvolucradasenelprocesodesaneamiento,titulaciónyregistro (MinisteriodeVivienda,Justicia,municipalidades,ONARP).Porelcontrario,ladireccióndelregistrotradicional eneseentoncesestabaen manos defuncionarios públicosynoexistíarepresentación delos usuariosnide las instituciones directamente involucradas en el proceso de saneamiento y titulación.

57 Losformulariossondocumentosestandarizadosyprerredactadosparacomplementarúnicamentelosdatos registralesrelevantesdelpredio,sustitularesylosactossobreaquel,locualfacilitaelingresodeinformación al sistema de cómputo. Ello permite un registro masivo y evita errores que suelen generarse cuando la descripcióndeáreas,linderosymedidas perimétricasestáexpresadadeformanarrativaeimprecisa.Según 
- Elimina requisitos que no estén directamente relacionados con la prueba del derecho a inscribir, por ejemplo la exigencia de acreditar el pago de impuestos ${ }^{58}$.

- En aplicación del principio de desregulación de las funciones públicas, se traslada a profesionales privados (ingenieros o arquitectos colegiados) la responsabilidad de verificación de información sobre ubicación, linderos y características físicas de los inmuebles y se les hace responsables de la realidad de la información contenida en los planos y formularios que firman. También se establecen mecanismos de supervisión y sanción por infracciones ${ }^{59}$.

- Las tarifas o aranceles registrales son fijados en base al [sic] costo del servicio registral (no por el valor del acto) ${ }^{60}$.

- Su nuevo sistema registral es computarizado, con capacidad para procesar inscripciones masivas y mecanismos efectivos de acceso a la información, sin riesgos de alteración o pérdida de ésta ${ }^{61}$.

- Su base geográfica permite conocer con precisión la ubicación y características del predio, relacionándolos con los datos de su titular y de los diversos actos y transacciones inscritos en el registro ${ }^{62}$. Se elimina, por tanto, el riesgo de duplicidad de inscripciones y superposición de áreas. La formación de la base geográfica no requiere del levantamiento de una nueva cartografía de alta precisión, sólo de información relevante para el saneamiento físico y legal de los predios y la definición de los derechos de propiedad sobre éstos $[\mathrm{sic}]^{63}$.

el Decreto Legislativo 495, los formularios podían ser suscritos por notarios y por abogados colegiados inscritos en el Índice de Profesionales del Registro Predial -luego del RPU y SUNARP-, con lo cual los usuarios podían elegir entre un vasto universo de profesionales con atribuciones para legalizar sus títulos y autorizar su inscripción en el registro. No obstante, al promulgarse la Ley 27755 (vigente desde junio de 2004), que dispone la unificación de los registros de predios en el Perú, se eliminaron los formularios registralesfirmadosporabogados; enconsecuencia,loscostosdeaccesoypermanenciaenlaformalidadse elevaron.Segúnelartículo7 de dicha ley, soloseautorizan los formularios registrales que lleven lafirmade notarios y únicamente para los casos de predios cuyo valor es inferior a 20 UIT.

58 Según el texto original de la Ley de Tributación Municipal (Decreto Legislativo 776), en caso alguno, registradoresynotariospúblicospodíanrequerirlaacreditacióndel pagodelimpuestopredialydealcabalaa efectosdecertificaroinscribiractos jurídicos,enelentendidodequelaresponsabilidaddefiscalizarelpago dedichostributoslecompeteexclusivamentealasautoridadesmunicipales.Noobstante,laLey27616(2001) modificóestecriterioyestableciólaobligatoriedaddeacreditarel pagodedichosimpuestosparalegalizary registrartransferenciasdepropiedad.Lamentablemente,ellohapropiciadotransacciones informalessobre predios y no ha incrementado la recaudación tributaria.

59 Por ejemplo, para inscribir el área, los linderos y las medidas perimétricas de un predio, para convertirlas a un nuevo sistema de medición y rectificar las ya registradas, solo se requiere de planos firmados por los profesionalesresponsablesdesuelaboración, másnoesnecesarioqueestosseanaprobadosenunproceso administrativo o judicial previo.

60 Noobstante, esto hasido modificadoal integrarse este registroal registro de predios. Hoy, al igual queen los otrosregistros,elarancel porcalificaciónregistralestárelacionadoconelvalordel predioodelactoainscribir.

61 Lasinscripcionesserealizanatravésdeunsistemacomputarizadodeprocesamientodedatos, enreemplazo del manejo manual de partidas registrales que entonces erautilizado por el sistematradicional de registro.

62 En las partidas registrales se vincula información jurídica y espacial; ello permite elaborar un inventario físicocodificadodetodos los predios registrados, unasuertedecatastroregistralquepuedeserfácilmente actualizado.

63 ElsistemaCOFOPRI-RegistroPredialUrbano(RPU)utilizóinformaciónpreexistente,básicamentecartografía desarrolladaporproyectosderegularizacióndetierrasruralesacargodelMinisteriodeAgricultura,lacualfue adecuadaparasuutilizaciónenáreasurbanas. Ellopermitióunahorrosustancialencostosdeformalización yelRPUlogróimplementarunsistemaseguroypocoonerosoparaidentificarinmueblesqueseasientaenel sistemaplanimétricooficialdelInstitutoGeográficoNacional.MorRis Guerinonı,Felipe,VíctorEndoOLASCUAGA 
A mediados de los noventa, uno de los principales retos en el Perú era el diseño de un único sistema registral que estuviese basado en el sistema del RP y que progresivamente fuera reemplazando al sistema tradicional de registro. En consonancia con este propósito, a fines de 1990 se amplió la competencia del RP para registrar predios rurales a nivel nacional. Desafortunadamente, en 1996 el gobierno peruano decidió crear un tercer registro de la propiedad - la Sección Especial de Predios Rurales (SEPR) ${ }^{64}$ - al cual le asignó competencia para registrar predios rurales en todo el país — con excepción del Departamento de Lima, respecto del cual el RP mantuvo competencia- ${ }^{65}$. Evidentemente, la coexistencia de tres registros de propiedad, con distintas normas, sistemas, autoridades y prioridades, generó una serie de problemas: entre los principales se contaron la falta de coordinación entre estos y la inseguridad legal resultante de inscripción de propiedades en más de un registro, la multiplicidad de títulos inscritos en favor de diversos titulares y la superposición de áreas entre predios inscritos. A fin de dar solución a dichos problemas, en el año 2004 se dispuso la unificación de todos los registros de propiedad predial, con lo cual tanto el RP como la Sección Especial de Predios Rurales y el Registro de la Propiedad Inmueble pasaron a ser parte del nuevo Registro de Predios. No obstante, hasta la fecha, la unificación solo se ha producido en la «letra de la ley»: cada registro continúa trabajando con su propio sistema. En el caso del RP, este ha ido perdiendo algunas bondades o ventajas — que sería importante recuperar- que tenía respecto del sistema tradicional de registro. En la actualidad, la Superintendencia Nacional de los Registros Públicos (SUNARP) es responsable de diseñar el sistema registral en base al cual se haría realidad la unificación de todos los sistemas de registro de propiedad predial en el Perú. Para dicho efecto, sería recomendable que éste se construya sobre la base del sistema del RP.

8. Una estrategia integral para coordinar todas las reformas, iniciativas y programas dirigidos a la protección y a la capitalización de los derechos de propiedad, la promoción de inversiones, el manejo eficiente de los recursos naturales y la protección efectiva del medio ambiente. En la gran mayoría de casos, los sistemas legales están plagados de normas confusas —e incluso contradictorias - que son aplicadas por una multiplicidad de entidades — tanto públicas como privadas - que carecen de una visión integral

y Rafael Ugaz Vallenas. La formalización de la propiedad en el perú, develando el misterio. Lima: Cofopri, Proyecto de Derechos de Propiedad Urbana - Banco Mundial, Servicios Editoriales del Perú, 2004, p. 82. 64 No obstante, el sistema registral de la SEPR no cuenta con las características y ventajas del sistema delRP antes señaladas. Entre las carencias más importantes, figuran la falta de base geográfica, lo cual le impide una plena interrelación entre el aspecto físico (ubicación y características del predio) yel aspecto jurídico del predio (derechos, actos y contratos inscritos, relativos al predio). Por tanto, el sistema registral de la SEPR-aligual queeldel registrotradicional-noestáen capacidad deenlazarelcontenidodelas partidas registralescon losmapasnicon lainformacióncatastralquehavenidoelaborandoel PETT. Ellohagenerado problemas demultiplicidaddetitularidadessobrelosprediosinscritos, superposición deáreasylinderosy desactualización de la información registral y catastral.

65 Con la creación de Cofopri, en 1996, como entidad rectora del programa de formalización de la propiedad en áreas urbanas, se brindó autonomía financiera al RP y se lo denominó Registro Predial Urbano (RPU). Tambiénseampliósucompetenciaatodotipodeposesionesinformalescuyaregularizaciónestabaacargo de Cofopri. Sin embargo, se redujo su competencia a los predios rurales ubicados en el Departamento de Lima: el resto pasó a la nueva Sección Especial de Predios Rurales (SEPR) a cargo de SunARP. 
de las reformas y del proceso legal en su conjunto. Asimismo, muchos gobiernos carecen de estrategia política para armonizar los diversos tipos de reformas y programas destinados a formalizar y capitalizar derechos de propiedad sobre activos inmobiliarios, facilitar el acceso a la tierra y a la vivienda a personas de menores recursos, fortalecer la seguridad ciudadana, prevenir o disminuir los riesgos asociados a desastres naturales, racionalizar y optimizar el manejo de recursos naturales, y estimular la inversión privada. En lo que respecta específicamente a la asignación y a la regularización de la propiedad predial, usualmente se registra una falta de coordinación y superposición de competencias entre las diversas entidades involucradas.

En el caso del Perú, unas las principales reformas para la formalización de la propiedad consistió en la creación de la Comisión para la Formalización de la Propiedad Informal (COFOPRI) en 1996, cuyo propósito era complementar y perfeccionar las reformas iniciadas a finales de la década de 1980, dirigidas a establecer mecanismos simplificados, seguros y masivos para la formalización de la propiedad en el Perú ${ }^{66}$. Originalmente, COFOPRI era responsable de la formalización de la propiedad en áreas urbanas $^{67}$. En 2007, sus funciones fueron extendidas temporalmente a áreas rurales ${ }^{68}$. En lo que respecta a tierras de las comunidades campesinas y nativas, la competencia para su formalización está repartida temporalmente de la siguiente forma: COFOPRI es competente con respecto a comunidades campesinas en doce regiones del país; y las direcciones regionales agrarias son competentes para regularizar derechos de propiedad de las comunidades campesinas en el resto de las regiones y de todo el universo de comunidades nativas del país ${ }^{69}$.

66 «Con las reformas legales introducidas en el sistema legal peruano, a finales de la década 1980, se simplificaron drásticamente los trámites de titulación y registro de asentamientos humanos a cargo de las municipalidades y del Registro de la Propiedad Inmueble. Los problemas no sólo radicaban en la excesiva duración y complejidad de los trámites para la formalización, sino en la mala calidad de los títulos emitidos por las municipalidades (multiplicidad de títulos sobre un mismo lote, otorgamiento de derechos a quienes no eran sus verdaderos poseedores y errores en la información contenida en los títulos). Ello con frecuencia daba lugar a disputas en torno a la propiedad, siendo dichos títulos generalmente rechazados por los registros públicos [...]. Gracias a las reformas legales aprobadas, el procedimiento para regularizar propiedad se redujo de un promedio de 15 a 20 años a sólo 2 meses. Posteriormente, con la creación de [...] CofopRI en 1996 y la promulgación de normas complementarias se simplificaron aún más los procedimientos de formalización para toda la gama de posesiones informales, lográndose no sólo la extensión del sistema de formalización a nivel nacional, sino un récord en materia de regularización de la propiedad [...]". DeLGADo. Extralegalidad y propiedad predial en América Latina... Op. cit., pp. 411 y 412.

67 Su competencia en áreas urbanas es temporal y debe ser transferida progresivamente a los gobiernos locales en los próximos tres años (diciembre 2011).

68 Entre1992y2007,dichacompetenciaestuvoenmanosdelPETr.Alfusionarseconesteen2007,lasfunciones de CoFOPRI se extendieron temporalmenteaáreas rurales y deberán ser transferidas progresivamentea los gobiernos regionales en los próximos cuatro años (diciembre 2012).

69 Desde 2007 -y como herencia del PETT-COFOPRI es competente para formalizar tierras de comunidades campesinas en doce regiones del país. Las direcciones regionales agrarias -que dependen política y normativamente del Ministerio de Agricultura - la tienen para el resto de comunidades campesinas y para todas las nativas. Sin embargo, estas funciones también son temporales y deben ser transferidas progresivamente a los gobiernos regionales en los próximos cuatro años (diciembre 2012). 


\section{Principales características de CofOPRI}

- Se trata de una entidad pública creada por ley (decreto legislativo 803, 1996). Se creó bajo mandato del Presidente de la República, pero hoy está adscrita al Ministerio de Vivienda, y su titular es nombrado por el presidente (decretos supremos 019-2006-Vivienda y 025-2007-Vivienda). Cuenta con autonomía administrativa, económica y financiera. Está provista de funciones ejecutivas y regulatorias para:

— diseñar, implementar y manejar programas de formalización de la propiedad de predios urbanos y rurales a nivel nacional, incluido levantamiento catastral;

- apoyar la implementación de mecanismos para la solución de disputas;

— apoyar la creación de oficinas registrales descentralizadas a nivel nacional e implementar mecanismos para promover la permanencia de las propiedades formalizadas en la legalidad;

- establecer mecanismos que faciliten el acceso al crédito y a servicios públicos;

— establecer mecanismos de coordinación con otras entidades públicas involucradas;

- llevar a cabo un inventario de familias pobres que demandan acceso legal a la vivienda y de las tierras de propiedad del Estado que pudieran ser utilizadas para dicho fin;

- establecer mecanismos para retroalimentar la reforma y perfeccionar el sistema de formalización de la propiedad y el nuevo sistema registral; y

— dar apoyo técnico y entrenamiento a gobiernos locales y regionales para la transferencia de funciones de formalización.

9. Un sistema de información y otros mecanismos para facilitar el acceso al crédito y el uso económico de predios formalizados. Un mecanismo fundamental para estimular no solo la formalización de la propiedad, sino su utilización económica es, por un lado, contar con un sistema simplificado de constitución y ejecución de garantías hipotecarias y prendarias. Por otro lado, también es crucial contar con un sistema de información que permita a potenciales acreedores y contratantes acceder de manera oportuna a data actualizada sobre predios, empresas y sobre las actividades económicas que sus titulares realizan a diario. Generalmente, ningún registro lleva cuenta de esta importante data.

Un ejemplo del tipo de mecanismo antes referido es el sistema de información a cargo de la Central de Información Positiva (CIP) de CofoprI,

\section{EL DERECHO A LA PROPIEDAD


que fue creado en el Perú en 2001. El CIP «[...] maneja información de 1.4 millones de propietarios formalizados [...] Fue creado sobre la base de la información correspondiente a las propiedades formalizadas por COFOPRI, e inscritas en el Registro Predial Urbano [...] y se nutre de información proveniente del registro predial y de diversas entidades públicas y privadas» ${ }^{70}$. El cruce de información de los propietarios formalizados por COFOPRI con la información de distintas instituciones públicas y privadas posibilita la generación de un perfil socioeconómico de los propietarios de predios formalizados, lo cual mejora su calificación como sujetos de crédito y muestra a los agentes económicos las oportunidades de generación de nuevos negocios ${ }^{71}$. Dicho perfil permite conocer «[...] la situación laboral del propietario, si es dependiente o no del sistema de pensiones y de seguridad social, el tiempo de aportaciones a la seguridad social, si tiene deudas en el sistema financiero y cuál es su hábito de pago, la validez de su documento de identidad, si posee vehículos que eventualmente pudieran servirle de garantía, entre otra información de interés para las entidades financieras» ${ }^{72}$.

10. Mecanismos para construir consenso en torno a la aprobación e implementación de las reformas propuestas e instrumentos para su permanente retroalimentación. En realidad, la construcción de consenso resulta indispensable no solo para lograr la aprobación de las reformas requeridas, sino también para su efectiva y satisfactoria implementación. La realidad nos ha demostrado que las reformas mejor intencionadas están destinadas al fracaso si no logran captar el apoyo de los supuestos beneficiarios y de los diversos actores públicos y privados involucrados. También es necesario ubicar este tipo de reformas en la cima de la agenda política e involucrar en su diseño e implementación a jefes de Estado y a funcionarios públicos responsables de la toma de decisiones al más alto nivel político. Se requiere, asimismo, de mecanismos que, por un lado, garanticen la consulta y participación ciudadana durante los procesos de creación y aplicación de las reformas, y que, por otro, permitan el monitoreo de sus resultados y el perfeccionamiento de normas y procesos para su adecuación a nuevas circunstancias.

La experiencia del Programa Peruano para la Formalización de la Propiedad en áreas urbanas ha demostrado la importancia de establecer mecanismos apropiados de comunicación e interacción con potenciales beneficiarios y diversos actores involucrados. Durante una década —desde mediados de los ochenta hasta mediados de los noventa- se estableció una serie de mecanismos legales y operativos para vencer resistencias y facilitar tanto la aprobación de las reformas propuestas como

70 Talesinstitucionesson, porejemplo,laSUNARP, laSuperintendenciadeBancaySeguros,laSuperintendencia deAdministración Tributaria,RENIEC,elSistemadeSeguroSocialdeSalud,laOficina NacionaldePensiones, el Banco de Materiales, EdeLNOR, Luz del Sur y SEDAPAL. En <www.cofopri.gob.pe>, citado en DeLGADo. «La formalización de la propiedad predial en el Perú». Op. cit., pp. 67 y 68.

71 Lamentablemente, Cofopri ha enfrenta ciertas dificultades para actualizar la información del CIP. Hoy se están evaluando diversas alternativas para optimizar la administración del sistema y el manejo de la data.

72 En <www.cofopri.gob.pe>. DeLGADO. «La formalización de la propiedad predial en el Perú». Op. cit., p. 68. 
su implementación y monitoreo. Para dicho efecto, se publicaron proyectos normativos — con exposición de motivos y análisis costo-beneficio- en los principales diarios del país y se convocó a la ciudadanía para que emitiese opinión; se realizaron audiencias públicas para discutir su contenido y perfeccionar la reforma, y se organizaron reuniones con diversos actores involucrados - líderes de organizaciones de base, funcionarios públicos, políticos y representantes de gremios y organizaciones de profesionales, de propietarios y de empresarios, etcétera-. Además, se difundió el contenido de las principales normas aprobadas, vía spots en radio y televisión, avisos publicitarios en diarios de circulación nacional y local, y paneles ubicados en diversas instituciones públicas y privadas. También se diseñó una metodología para lograr un máximo de participación ciudadana durante la ejecución de los programas de formalización.

\section{RESULTADOSDELOS PROGRAMAS DEFORMALIZACIÓN DE LA PROPIEDAD EN PERÚ}

En lo que respecta a la formalización de la propiedad en áreas urbanas, gracias a la creación de COFOPRI y a la promulgación de diversas normas dirigidas a perfeccionar la reforma, se logró no solo la extensión del sistema de formalización a nivel nacional, sino un récord en materia de regularización de la propiedad, motivo por el cual dicho sistema fue calificado por el Banco Mundial (BM) y por otros organismos internacionales como uno de los más exitosos del mundo. A continuación, un recuadro da cuenta sintetizada de tales resultados.

\section{Principales logros del sistema Cofoprl-Registro Predial al 2007³}

— «Más de 8 millones de peruanos y peruanas, gran parte de los cuales se encuentran por debajo de la línea de la pobreza, se convirtieron en legítimos propietarios de sus viviendas (Estimados COFOPRI e ILD).

— La formalización y registro de más de 1.7 millones de títulos de propiedad sobre predios urbanos a nivel nacional. (Estimados COFOPRI ${ }^{74}$.

- Un significativo incremento en inversión y consolidación urbana, que se tradujo en la mejora de materiales de construcción y acabado de las viviendas, extensión de servicios de abastecimiento de agua y conexión a sanitarios, mayor incidencia de alumbrado público, reducción en distancias a vías de transporte y centros sociales, mayor

EL DERECHO A LA PROPIEDAD COMO

DIMENSIÓN DEL DERECHO A LA IDENTIDAD 
probabilidad de contar con teléfono y de realizar negocios en la vivienda. (Estimados COFOPRI) ${ }^{75}$.

—El valor de los activos prediales formalizados se elevó en US\$12,800 millones de dólares (Estimados ILD) ${ }^{76}$.

— Los ingresos de los propietarios de predios formalizados se incrementó en unos US\$ 5,100 millones de dólares (Estimados ILD) ${ }^{77}$.

- El monto de créditos otorgados a los propietarios de predios formalizados se incrementó $280 \%$ en seis años (2000-2006), y el número de prestatarios en $211 \%$, constituyendo el $11 \%$ de los prestatarios del sistema financiero formal. El $71 \%$ de los créditos otorgados por el sistema financiero formal provinieron de Bancos (Estimados COFOPRI y Superintendencia de Banca y Seguros - SBS).

— Los propietarios de predios ahorraron unos US\$200 millones en costos burocráticos (Estimados ILD).

- Se redujeron las diferencias de género entre hombres y mujeres. Por un lado, el 53\% de los propietarios formalizados son mujeres. Por otro, aquellas han sacado ventaja en los créditos orientados a la microempresa, con un $54 \%$ frente al $46 \%$ de los hombres, lo cual evidencia la consolidación de la participación femenina en este segmento (Estimados CofOPRI y SBS) ${ }^{78}$.

— La probabilidad de trabajo infantil se redujo en un 28\% (Estimados Universidad de Princeton) ${ }^{79}$.

— Los conflictos en torno a la propiedad predial se redujeron sustancialmente (Registro Predial e ILD).

- Se fortaleció la presencia del Estado en áreas formalizadas y se desplazó a grupos terroristas de dirigencias de asentamientos humanos y organizaciones de base (Registro Predial e ILD) $»^{80}$.

75 RivAS-LLOSAM., Roddy. «Informefinal delestudiodelefectodelatitulación deCoFoPRIsobrelainversiónenla infraestructurayelniveldeconsolidaciónenáreasurbanas", realizadoporencargodeCoFoprientrefebrero y abril de 2004.

76 Cabe señalar que, en investigaciones realizadas en Lima por Erika Field (Universidad de Princeton), se encontró que la titulación está asociada con un aumento de $68 \%$ de la tasa de renovación del hogar luego decuatroaños de haber recibidoeltítulo. FIELD,Erika. «PropertyRightsandInvestmentinUrbanSlums». En <http://www.economics.harvard.edu/faculty/field/papers/FieldinvestJEEA.pd>.

77 Field encontró que la titulación está relacionada con una mayor oferta de trabajo. Según ella, el $47 \%$ de quienes no tenían un título de propiedad en el grupo estudiado invertía en promedio más de trece horas semanales en proteger sus viviendas. Se encontró que las familias que recibieron título de propiedad dedicabanmástiempoatrabajarfueradecasa-especialmentelasmujeres-,porloquepudieronacceder amejores oportunidades laborales y elevar sus ingresos. Deacuerdo con Field, las familias poseedoras de viviendas formalizadas por CoFopri habían logrado aumentar su tiempo de trabajo en cerca de 45 horas por semana.Con el salario mínimo vigente en el momento de laestimación, ello representaba cercade US\$118 de ingreso adicional mensual por familia. FiELD, Erika. «Entitled to Work: Urban Property Rights and Labor Supply in Peru». En <http://www.economics.harvard.edu/faculty/field/papers/Field_COFOPRI.pdf>.

78 En <www.cofopri.gob.pe>.

79 Field encontró que la titulación ha traído beneficios a los hijos de las familias que recibieron un título. De acuerdo con su estudio, dichas familias son menos propensas a enviar a sus pequeños hijos a trabajar y másinclinadasaenviarlosaestudiar, aparentemente porquesus ingresosaumentangraciasaquepueden trabajar más horas fuera de la casa y necesitan menos de los ingresos del trabajo infantil. FIELD. «Entitled to Work...». Op. cit.

80 Elsistemadeformalizacióndelapropiedadfueun ingredientedelaluchacontraelterrorismoenelPerú.[...] ElgrupomaoístaSenderoLuminosobuscabaganarlegitimidadentrelospobresgarantizandosusderechos de propiedad, lo cual el Estado en ese momento no podía hacer. Dicho grupo había organizado invasiones y titulación en diversos pueblos jóvenes de Lima, tales como Raucana, Vitarte y Huaycán. Sendero fue derrotado mediante un operativo de inteligencia contra su cúpula y mediante la lucha contra sus filas en la selva. Pero estas victorias no hubieran sido posibles ni suficientes si no se derrotaba a Sendero en la 
En relación con la formalización de la propiedad en áreas rurales, hasta el año 2007 se habría logrado la regularización de 1.8 millones de títulos de propiedad a nivel nacional, los cuales fueron inscritos en la Sección Especial de Predios Rurales antes referida ${ }^{81}$. No obstante, deficiencias normativas y del Proyecto Especial de Titulación de Tierras Rurales (РЕтT) han puesto en tela de juicio la solidez de los títulos entregados por este. Entre los problemas más graves se cuentan los errores contenidos en los títulos, la duplicidad de titulares sobre un mismo predio y la superposición de áreas entre predios inscritos, generados estos últimos en vista de que sus registros carecen de base geográfica ${ }^{82}$. Además, los errores y los casos de corrupción durante la regularización de la propiedad han generado graves conflictos - especialmente entre colonos y miembros de comunidades campesinas y nativas - ${ }^{83}$.

En lo que respecta a la situación de las comunidades campesinas y nativas en el Perú, a pesar que, de acuerdo con la información oficial, más del $80 \%$ de las comunidades reconocidas habrían sido tituladas y los derechos de propiedad sobre sus tierras inscritos en los registros públicos ${ }^{84}$, la gran mayoría de estas carece de plena seguridad legal sobre sus tierras y enfrenta conflictos de linderos con otras comunidades o con terceros ${ }^{85}$. En el caso de comunidades nativas, la situación se agrava porque el $86 \%$ de sus tierras no están adecuadamente delimitadas - no cuentan con coordenadas UTM (de referencia universal) para su ubicación geográfica y se basan en sistemas arcaicos de delimitación- ${ }^{86}$. Por otro lado, un porcentaje muy reducido de miembros

mente de las personas y en el terreno de las ideas. La forma fue demostrándoles la legitimidad del Estado, al ser capaz de dar reconocimiento legal a los derechos de propiedad que los pobres habían empezado a construir en la extralegalidad, y al demostrarles que no necesitaban de Sendero para hacerlos valer". DE Sото, Hernando. El otro sendero. Lima: Empresa Editora El Comercio, 2000, p. 22.

81 Esta cantidad de títulos corresponde al $25 \%$ del total de inmuebles inscritos en el registro de predios. Si sumamosaestoslos 1,7 millonesdetítulosformalizadosenáreasurbanas,ellosignificaríaque,enprincipio, Cofopri y PETt habrían formalizado e inscrito el $\mathbf{5 0 \%}$ del total de los títulos registrados en Perú.

82 Recordemos que, mientras la inscripción de los predios formalizados por CofopRI se realizaba en el Registro Predial — que tiene base geográfica y un sistema moderno de procesamiento de datos-, los predios regularizados por el PETT se registraban en la Sección Especial de Predios Rurales, que, como ya se dijo, carecía de estas ventajas.

83 Existe evidencia de que la mayoría de predios formalizados por el PETT durante la Fase 1 del Programa Titulación y Registro de Tierras presentan superposición de derechos con predios adjudicados en favor de terceros por el propio Ministerio de Agricultura. Un ejemplo es el caso de los predios en la provincia de Huanta, los que, en su gran mayoría, presentan duplicidad de partidas registrales con predios inscritos con anterioridad en el registro. También hay casos de superposición de derechos con áreas naturales protegidas y predios declarados como Patrimonio Cultural de la Nación por el INC, situación que no ha sido regularizada hasta el momento. Además, en 2005, había más de 70 mil rectificaciones pendientes por error en los títulos. ORMEÑo LUNA, Ivette. «Diagnóstico sobre los principales obstáculos para la formalización de los predios rurales, territorios de comunidades campesinas y tierras eriazas en el Perú y propuestas de reforma». Informe preparado por encargo del ILD, 2006.

84 De acuerdo con el oficio $\mathrm{N}^{\circ}$ 012-2007-COFOPRI/DE, existen 7.563 comunidades indígenas reconocidas en Perú(6.066comunidadescampesinasy 1.497 comunidadesnativas), queocupanmás del $26 \%$ delterritorio nacional-unas 34 millonesdehectáreas-(23millonescorrespondenalascampesinasy11alasnativas)-. Las tierras de más del $83 \%$ de comunidades reconocidas $(6.299 ; 5.039$ campesinas y 1.260 nativas) habrían sidotituladaseinscritasenlos registrospúblicos. Enelcasodecomunidadesnativas, seentregantítulosde propiedadsobretierrasdeusoagropecuario-querepresentanun $60 \%$ detotaldesuterritorio-ycontratos de uso sobre tierras forestales - que representan el otro $40 \%$ -

85 Un $57 \%$ de las comunidades tiene conflictos con otras comunidades o con terceros. En Amazonas, el $100 \%$ de comunidades tiene problemas. Esan. Op. cit., p. 10.

86 Deacuerdocon información oficial del PETT, del total de comunidades nativas tituladas, aproximadamente el $86 \%$ no cuenta con coordenadas de ningún tipo. El $13 \%$ cuenta con coordenadas UTM, pero con puntos tomados de la carta nacional. El $1 \%$ restante responde a planos con coordenadas arbitrarias. 
de comunidades campesinas habría recibido títulos sobre las parcelas que explotan individualmente ${ }^{87}$. Además, durante la última década, los programas de titulación ejecutados — a cargo de COFOPRI, PETT y las direcciones regionales agrarias - se han concentrado en áreas urbanas y rurales, y en algunos casos también a comunidades campesinas. Lamentablemente, la atención brindada a la titulación de comunidades nativas ha sido prácticamente nula ${ }^{88}$.

\section{VI.PRINCIPALES RETOS Y LECCIONES APRENDIDAS}

Los retos a enfrentar hoy en día son muchos. Entre los más relevantes podemos citar los siguientes:

- En la gran mayoría de países en vías de desarrollo, está pendiente la creación de los instrumentos legales necesarios para garantizar el derecho a la identidad en su doble dimensión, lo que permitiría que las mayorías pobres puedan no solo acreditar su existencia legal sino también incorporar sus principales activos a una economía moderna e inclusiva. Dicha incorporación solo resultará posible si se cuenta con mecanismos simplificados y poco onerosos para identificar a las personas y para regularizar los diversos tipos de extralegalidad que afectan sus tierras, edificaciones y negocios.

- Debe ponerse especial atención en los organismos encargados de formalizar la propiedad. En el caso del Perú, es un tema que requiere de urgente atención, en la medida en que, durante los últimos años, se han desarrollado tres procesos paralelos: primero, la fusión de dos entidades públicas que durante más de una década tuvieron a cargo la formalización de la propiedad en áreas urbanas y rurales; segundo, la desatención de la cual, durante los tres últimos quinquenios, ha sido objeto la regularización de las tierras de las comunidades indígenas; y tercero, la proliferación de concesiones otorgadas para la producción de biodiesel y la exploración y explotación de recursos forestales y mineros e hidrocarburos, muchas de las cuales se superponen con los derechos que sobre esas mismas tierras tienen campesinos, colonos y comunidades campesinas y nativas. A ello se agrega la transferencia de las funciones de formalización de la propiedad predial. Durante los próximos cuatro años, estas serán transferidas a gobiernos locales y regionales, pese a que, en la mayoría de casos, estos no cuentan con la infraestructura, tecnología y recursos requeridos.

87 Solo 1,6\% de los predios de los miembros de comunidades campesinas habrían sido titulados por PETT; el $50 \%$ de los comuneros manifestó tener problemas con la titulación individual $(90 \%$ de las parcelas no está correctamente delimita; solo el $7 \%$ de los comuneros tiene planos de sus parcelas; en el $36,2 \%$ de las comunidadesexisten problemasdelinderosentrecomuneros, conmayorincidenciaeneldepartamentode Amazonas). Esan. Op. cit., pp. 2 y 14.

88 Casilatotalidad delostítulos delascomunidades nativas fueronentregados duranteelperíodo 1975-1999. 
- A pesar de las reformas introducidas y de la simplificación de trámites, la mayoría de procedimientos para acceder legalmente a la tierra urbana, rural y forestal, así como para parcelar las tierras, urbanizarlas y construir son aún complejos y onerosos. Como consecuencia, en países en desarrollo, la mayoría de personas parcelan sus tierras de facto y venden los lotes a terceros, con lo que dan origen a un vasto universo de parcelaciones y edificaciones no autorizadas. Asimismo, la gran mayoría de transacciones sobre activos prediales carecen de la debida documentación y nunca llegan al registro, por lo cual no son ejecutables ni oponibles a terceros - es decir, no tienen el carácter erga omnes-.

- Los costos de permanencia en la legalidad se han incrementado por diversos motivos, lo cual «[...] desincentiva la inscripción de los actos y transacciones que se realizan sobre los predios registrados y ocasiona la desactualización de la información registral y catastral» ${ }^{89}$. En el caso del Perú, por ejemplo, ello se debió, entre otros, a la exigencia de acreditar el cumplimiento de obligaciones ajenas a la prueba de la propiedad — tales como el pago de diversos impuestos- cada vez que se solicita la certificación legal y la inscripción de una transferencia, al aumento de las tasas registrales, y a la eliminación de formularios registrales firmados por abogado, lo cual dificultó el acceso a un título registrable.

Algunas de las lecciones aprendidas en materia de formalización de derechos de propiedad sobre activos prediales son las siguientes:

- Para garantizar el derecho a la identidad en su doble dimensión, la reforma «[...] debe ser diseñada 'a la medida' [...] [de] las características propias de cada lugar [...] [y] evitando imposiciones de modelos preestablecidos. Además [...] [se] debe construir sobre aquellas normas y prácticas extralegales que son utilizadas y respetadas por la mayoría de la población para acreditar y defender sus derechos y garantizar sus transacciones [...]» ${ }^{90}$.

- «[...] La formalización de la propiedad y la reforma del sistema registral no pueden desarrollarse de manera aislada [...] deben formar parte de un proceso integral dirigido a otorgar derechos de propiedad claros y seguros, que permitan fijar el potencial de los activos y hacerlos fungibles, integrar información dispersa, poner a las personas en red y proteger las transacciones $[\ldots]{ }^{91}$.

- «Facilitar el acceso a la formalidad es solo un primer paso $0^{92}$. Un segundo reto consiste en estimular la permanencia [...] dentro

89 Delgado. «La formalización de la propiedad predial en el Perú». Op. cit., p. 69. 90 Delgado. Extralegalidad y propiedad predial en América Latina... Op. cit., p. 437.

92 Esteprimerpasorequiere «[...]deprocedimientossimplificados, masivosyseguros[para]regularizar[...]el universodeactivospredialesafectadoporunniveldistintodeextralegalidad.Elloexigenosóloellevantamiento demapas, la informatización de procesos y [...]lamodernización de registros, sinoel saneamientolegal de los derechos de propiedad [...]. Reformas legales indispensables para dicho efecto son, por ejemplo, la

EL DERECHO A LA PROPIEDAD COMO

DIMENSIÓN DEL DERECHO A LA IDENTIDAD 
de aquélla [sic], para lo cual se requiere simplificar [...] una serie de procedimientos legales y abaratar costos de transacción [...]». También se requiere desarrollar sistemas de seguros y mecanismos financieros para facilitar el acceso al crédito. «Sin embargo, es evidente que $[. .$.$] [estas] reformas [...] constituyen la enorme$ tarea pendiente en la gran mayoría de países de América Latina $[\ldots])^{{ }^{93}}$.

- Para capitalizar los principales activos de las mayorías pobres se requiere, además, de mecanismos simplificados y poco onerosos que les permitan organizarse para desarrollar actividades empresariales, acceder al crédito, realizar contratos con terceros, acceder a un mercado ampliado y captar inversión privada.

- Las reformas en materia de propiedad no pueden limitarse a regularizar situaciones pasadas y hechos consumados «[...] La única forma de reducir las ocupaciones, subdivisiones, edificaciones y transferencias ilegales de tierras es brindando alternativas para que la población de menores recursos pueda acceder legalmente a éstas $[\ldots]\rangle^{94}$.

- El sistema legal debe establecer mecanismos apropiados para compensar a los propietarios por el uso y explotación de sus tierras, y por los eventuales daños que determinadas actividades económicas pudieran causar a la salud y al medio ambiente.

- El éxito de las reformas depende, en gran medida, de una buena estrategia para construir consenso en torno de ellas, así como de mecanismos adecuados para su difusión, consulta y participación ciudadana.

- «[...] La agenda para la reforma debe permanecer abierta [...] [con un] continuo [...] perfeccionamiento de las reformas realizadas y [estar] alerta respecto de decisiones que pudieran [...] poner en riesgo la inversión realizada y los logros obtenidos» ${ }^{95}$.

Una última reflexión es que las reformas hacia la inclusión solo pueden ser exitosas si los gobiernos dedican especiales esfuerzos a construir un puente institucional que permita conectar el derecho consuetudinario y las prácticas locales con un sistema jurídico de alcance nacional. No obstante, para ser genuinamente inclusivo, el Estado de derecho debe contar con una estructura legal y política suficientemente innovadora y sólida, que garantice la plena vigencia del derecho a la identidad de las grandes mayorías y que brinde los incentivos necesarios para estimular un tránsito masivo y sostenido hacia ella. 